\title{
Changes in levels of catalase and glutathione in erythrocytes of patients with stable asthma, treated with beclomethasone dipropionate
}

\author{
H.J. Pennings*, P.J.A. Borm ${ }^{+}$, C.T.A. Evelo", E.F.M. Wouters*
}

\begin{abstract}
Changes in levels of catalase and glutathione in erythrocytes of patients with stable asthma, treated with beclomethasone dipropionate. H.J. Pennings, P.J.A. Borm, C.T.A. Evelo, E.F.M. Wouters. (C)ERS Journals Ltd 1999.

ABSTRACT: In asthmatic patients, antioxidant defence is decreased. Although inhaled corticosteroids decrease asthmatic inflammation and modulate reactive oxygen species (ROS) generation, little is known of their effect on cellular antioxidant levels. The aim of this study was to evaluate the effect of inhaled beclomethasone dipropionate (BDP; $1,000 \mu \mathrm{g} \cdot \mathrm{day}^{-1}$ ) on erythrocyte antioxidant levels in stable asthmatic patients.

Forty patients with stable, mild asthma were treated in a double-blind, placebocontrolled, parallel-group study with BDP $250 \mu \mathrm{g}$, two puffs b.i.d. for 6 weeks. At entry and every 2 weeks during treatment, erythrocyte antioxidant levels, haematological parameters, pulmonary function tests and asthma symptoms were determined.

The results show that during treatment with BDP, erythrocyte catalase levels increased (at entry (mean \pm SEM) $41 \pm 4$, after 6 weeks $54 \pm 4 \mu \mathrm{mol} \mathrm{H}_{2} \mathrm{O}_{2} \cdot \mathrm{min}^{-1} \cdot \mathrm{g}$ haemoglobin $(\mathrm{Hb})^{-1}, \mathbf{p}=0.05$ in comparison with placebo). Erythrocyte total glutathione levels significantly decreased after 6 weeks treatment with BDP (from $7.0 \pm 0.4$ to $6.6 \pm 0.3$ $\left.\mu \mathrm{mol} \cdot \mathrm{g} \mathrm{Hb}^{-1}(\mathrm{p}=0.04)\right)$. In the BDP-treated patients, blood eosinophil counts were higher in patients who responded with an increase in erythrocyte catalase levels during BDP treatment, as compared to those not responding ((mean \pm SEM) $340 \pm 39$ and $153 \pm 52 \times 10^{6}$ cells $\cdot L^{-1}$, respectively, $p=0.05$ ).

The present study shows that treatment with inhaled bedomethasone dipropionate results in changes in antioxidant levels in erythrocytes of patients with stable, mild asthma.
\end{abstract}

Eur Respir J 1999; 13: 1260-1266.

Asthma is characterized by reversible airflow obstruction and the presence of a chronic inflammation within the airways. Cells involved in the inflammatory process in asthma have been shown to generate increased amounts of reactive oxygen species (ROS) [1-3] and levels of ROS generation correlate with asthma severity [4]. ROS-generation is enhanced in bronchoalveolar lavage (BAL) cells of stable asthmatics [5] and increases after antigen challenge [6]. ROS can influence airway cell function by interacting with deoxyribonucleic acid (DNA), altering protein structures, interfering with signal transduction mechanisms by oxidative modification (e.g. $\beta_{2}$-adrenergic receptors), contracting airway smooth muscle, increasing vascular permeability and increasing release of secondary inflammatory mediators (i.e. leukotrienes, platelet-activating factor) [7]. Within the lung, powerful antioxidant enzymes are present, both intra- and extracellularly, and the levels of these enzymes may increase following chronic exposure to increased levels of ROS $[8,9]$. Levels of glutathione have been shown to be elevated in BAL fluid of patients with stable asthma [10]. In asthma, ROS generation is not only increased within the pulmonary compartment, but also in peripheral blood cells $[1,3]$. This

\begin{abstract}
*Dept of Pulmonology, University Hospital Maastricht, Maastricht, the Netherlands. Depts of ${ }^{+}$Health Risk Analysis and Toxicology and "Pharmacology, Maastricht University, Maastricht, the Netherlands.
\end{abstract}

Correspondence: H.J. Pennings

Dept of Pulmonology

University Hospital Maastricht

P.O. Box 5800

6202 AZ Maastricht

The Netherlands

Fax: 31433875051

Keywords: Asthma

beclomethasone

catalase

glutathione

red blood cells

Received: July 291998

Accepted after revision January 151999

This study was supported by a grant from Glaxo Wellcome B.V., the Netherlands. observation is in line with data showing the presence of activated leukocytes in the general circulation after allergen challenge [11]. In asthma, evidence for a disturbed oxidant-antioxidant balance has been found in the general circulation. Decreased glutathione peroxidase levels have been reported in serum, platelets and red blood cells (RBC) [12, 13] and levels of selenium, a cofactor for glutathioneperoxidase, are reduced in asthmatic patients [13]. Decreased levels of catalase in RBC of asthmatic children have also been reported [14]. Recently, it was shown that the antioxidant capacity is decreased in plasma of asthmatic patients, both in stable and in acute asthma [15].

$\mathrm{RBC}$ can be regarded as circulating anti-oxidant carriers, reflecting exposition to $\operatorname{ROS}[9,16]$. The importance of $\mathrm{RBC}$ antioxidant enzymes in protecting target cells from ROS has been shown both in in vitro [17] and in vivo [18] studies. RBC antioxidative enzymes can be determined with a high degree of reproducibility and studies have shown that wide interindividual variations exist [19]. Since RBC are more easily accessible than lung tissue, RBC antioxidant levels have been used in studies evaluating chronic ROS exposure [16, 20, 21]. 
Corticosteroids play a dominant role in the treatment of asthma owing to their powerful anti-inflammatory effects [22]. So far, few studies have evaluated the effects of inhaled corticosteroids on antioxidant levels in asthma [23]. The aim of this study was to evaluate the influence of inhaled beclomethasone dipropionate (BDP) on antioxidant levels of RBC in patients with mild, stable asthma. The changes were chosen to be studied in RBC, since they represent a long-term index of antioxidant status [16].

\section{Materials and methods}

\section{Study design}

The present study was performed simultaneously with investigations into the effect of BDP on isocapnic hyperventilation with cold air, the results of which have been reported previously [24]. Forty patients with mild, stable asthma, equally distributed over both sexes, were included in the study. The study design consisted of a doubleblind, placebo-controlled, parallel-group study, in which patients were randomly allocated to receive either BDP $250 \mu \mathrm{g} \cdot$ puff $^{-1}$, two puffs b.i.d. by metered-dose inhaler or placebo (containing the propellant dichloride-difluoridemethane and trichloride-fluoride-methane) for 6 weeks. The time schedule consisted of a run-in period of 1 week, followed by a treatment period of 6 weeks, during which control visits were scheduled every 2 weeks. All patients entering the study had a documented bronchial hyperresponsiveness (defined as a provocative dose of histamine causing a $20 \%$ fall in forced expiratory volume in one second (PD20) value $<8 \mu \mathrm{mol}$ ) and were all atopic, with a mean number of positive skin tests for aeroallergens of $4.4 \pm 2.4$ (mean $\pm \mathrm{SD})$.

Patients were all in a clinically stable condition and showed no evidence of recent respiratory tract infection. None of the patients had been treated with inhaled or oral corticosteroids within the 3 months prior to the study. Only $\beta_{2}$-sympaticomimetic drugs were allowed for control of asthma.

During the study, patients recorded in a diary, asthma symptoms $(0=$ no complaints, $5=$ major interference with daily activities), the number of $\beta_{2}$-sympaticomimetic drugs used for control of asthma and peak expiratory flow rates (PEFR), using mini-Wright peak-flow meters (Airmed; Clement Clarke International Ltd., London, UK). Patients recorded the best of three successive measurements of PEFR in the morning and the evening. At every visit, the patient diary was reviewed and pulmonary function was evaluated by flow-volume measurements using a pneumotachograph (Masterlab, Jaeger, Würzburg, Germany).

The study was approved by the local medical ethical committee and written informed consent was obtained from all patients.

\section{Chemicals}

The following chemicals were used: superoxide dismutase (SOD; bovine erythrocytes), xanthine oxidase (cow milk) and glutathione reductase (yeast) and reduced (GSH) and oxidized (GSSG) glutathione (Boehringer Mannheim, Mannheim, Germany); xanthine, cytochrome C, haemo- globin $(\mathrm{Hb})$, sodium azide and $\alpha$-tocopherol (Merck, Darmstadt, Germany); $N$-ethylmaleimide and $o$-phthaldialdehyde (Aldrich, Steinheim, Germany); 1-chloro-2,4dinitrobenzene (CDNB), glutathione reductase (GR; type III) and reduced $\beta$-nicotinamide (NADPH) (Sigma, St Louis, MO, USA, for the determination of glutathione/ glutathione S-transferase; Boehringer Mannheim for the determination of glutathione peroxidase). All other chemicals used were of analytical quality. Only microfiltrated deionized water was used.

\section{Venous blood preparation}

Venous blood $(15 \mathrm{~mL})$ was collected in ethylenediominetetraacetic acid (EDTA)-coated tubes (Sherwood Medical, Balley-money, UK). White blood cell counts, cell differentiation as well as quantification of eosinophils was performed. For antioxidant analysis, blood was immediately stored at $4{ }^{\circ} \mathrm{C}$ after collection and processed within $2 \mathrm{~h}$. Subsequently, blood was centrifuged for $10 \mathrm{~min}$, $2,000 \times g$ at $4^{\circ} \mathrm{C}$. The buffy coat and plasma were removed and the RBC were washed with $10 \mathrm{~mL}$ phosphate-buffered saline (PBS), gently swirling the tube and afterwards RBC were centrifuged again for $10 \mathrm{~min}, 2,000 \times g$ at $4^{\circ} \mathrm{C}$. This procedure was repeated three times. After the washing procedure, samples were frozen in aliquots of $1 \mathrm{~mL}$ at $-70^{\circ} \mathrm{C}$ until analysis.

Glutathione peroxidase, superoxide dismutase and catalase activity

The activity of these enzymes was determined as described previously [20]. Haemoglobin was determined according to the method of VAN KAMPEN and ZIJLSTRA [25]. In brief, for glutathione peroxidase, $1 \mathrm{~mL}$ of haemolysate was mixed with an equal volume of potassium ferricyanide and $\mathrm{KCN}$ containing buffer. Fifty microlitres of the mixture was added to the incubation buffer containing $1 \mathrm{mM}$ GSH, $200 \mu \mathrm{M}$ NADPH and $1 \mathrm{IU} \cdot \mathrm{mL}^{-1}$ GSSG-reductase and the rate of oxidation of NADPH was followed for $3 \mathrm{~min}$ by spectrophotometry at $340 \mathrm{nM}$. The substrate used was $0.33 \mathrm{mM} \mathrm{H}_{2} \mathrm{O}_{2}$ for measurement of selenium dependent glutathione peroxidase. Units of enzyme activity were expressed as $\mu \mathrm{mol} \mathrm{NADPH} \cdot \mathrm{min}^{-1} \cdot \mathrm{mg}$ $\mathrm{Hb}^{-1}$ using a molar extinction coefficient for NADPH of $6.22 \times 10^{-3} \cdot \mathrm{mM}^{-1} \cdot \mathrm{cm}^{-1}$.

Superoxide dismutase activity was measured by the method of McCORD and FrIDOvich [26]. A standard curve was prepared using commercially available SOD. The enzyme activity at $25^{\circ} \mathrm{C}$ was expressed in units of enzyme per mg $\mathrm{Hb}$.

Catalase activity was measured according to AEBI [27], as described previously. Prior to the catalase measurement, lysates were diluted to a concentration of $50 \mathrm{mg}$ $\mathrm{Hb} \cdot \mathrm{mL}^{-1}$. At $25^{\circ} \mathrm{C}, 4 \mu \mathrm{L}$ lysate and $1 \mathrm{~mL} \mathrm{H}_{2} \mathrm{O}_{2}(30 \mathrm{mM})$ were added to $2 \mathrm{~mL}$ PBS. The rapid decomposition of $\mathrm{H}_{2} \mathrm{O}_{2}$ was followed during $15 \mathrm{~s}$ from the decrease in absorbance at $240 \mathrm{~nm}$. Enzyme activity was expressed as mmol $\mathrm{H}_{2} \mathrm{O}_{2} \cdot \mathrm{min}^{-1} \cdot \mathrm{g} \mathrm{Hb}^{-1}$ using a molar extinction coefficient for $\mathrm{H}_{2} \mathrm{O}_{2}$ of $0.0394 \mathrm{mM}^{-1} \cdot \mathrm{cm}^{-1}$.

Total glutathione (reduced plus oxidized) and glutathione S-transferase were determined as described previously [21]. In brief, for determination of total glutathione, 
RBC were treated with an equal volume of $10 \%(\mathrm{w} / \mathrm{v})$ trichloroacetic acid. Supernatants were diluted 9-fold with $100 \mathrm{mM}$ sodium/potassium buffer $(\mathrm{pH}$ 7.4) and measured using the cyclic oxidation-reduction method essentially as described by ANDERSEN [28].

For determination of glutathione S-transferase (EC 2.5.1.18) activity with CDNB as a substrate, full lysis of the thawed cells was induced with 5 volumes of ice-cold water (10-15 min), using the method of HABIG and JACOBY [29] with previously described modifications [30].

\section{Statistics}

All data described are mean \pm SEM, unless otherwise specified. Effect of treatment was expressed as changes from baseline. Since antioxidant enzyme levels were not distributed normally, nonparametric tests were used for analysis between treatment groups (Mann-Whitney Utest). A p-value $<0.05$ was considered statistically significant (two-sided test). Correlations between parameters were evaluated using the Spearman's rank correlation coefficient. The statistical package SPSS/PC+ (version 6.1Windows; SPSS Inc., Chicago, IL, USA) was used for all calculations.

\section{Results}

Forty patients were included in the study. Demographic variables are given in table 1. As reported previously, patients in the BDP group demonstrated a significantly higher FEV1 than the placebo group (101 versus 92\% predicted, $\mathrm{p}=0.02$ ). Eighteen patients in the BDP group and 17 patients in the placebo group completed the study. In the placebo group, the main reason for dropping-out was withdrawal of consent (three patients), whereas in the BDP group exacerbation of eczema, necessitating oral corticosteroid treatment (one patient) and noncompliance (one patient) were the reasons for exclusion from the study.

Table 1. - Subjects characteristics: anthropometric and spirometric data

\begin{tabular}{|c|c|c|}
\hline & $\mathrm{BDP}$ group & Placebo group \\
\hline Sex M/F & $10 / 10$ & $10 / 10$ \\
\hline Smokers yes/no & $4 / 16$ & $4 / 16$ \\
\hline Age yrs & $29 \pm 7$ & $28 \pm 6$ \\
\hline Height $\mathrm{cm}$ & $172 \pm 7$ & $172 \pm 12$ \\
\hline Weight $\mathrm{kg}$ & $75 \pm 12$ & $74 \pm 14$ \\
\hline FEV1 \% pred & $101 \pm 12$ & $92 \pm 12$ \\
\hline PD20 $\mu \mathrm{mol}$ & $1.3 \pm 1.3$ & $1.1 \pm 1.9$ \\
\hline Haemoglobin $\mathrm{mmol} \cdot \mathrm{L}^{-1}$ & $8.7 \pm 0.6$ & $9.1 \pm 0.8$ \\
\hline Leukocytes $\times 10^{9}$ cells $\cdot \mathrm{L}^{-1}$ & $6.3 \pm 2.0$ & $7.1 \pm 2.0$ \\
\hline Eosinophils $\times 10^{6}$ cells $\cdot \mathrm{L}^{-1}$ & $318 \pm 148$ & $298 \pm 229$ \\
\hline $\operatorname{IgE} \mathrm{kU} \cdot \mathrm{L}^{-1}$ & $430 \pm 519$ & $516 \pm 911$ \\
\hline
\end{tabular}

Data are presented as mean \pm SD. BDP: beclomethasone dipropionate; M: male; F: female; FEV1: forced expiratory volume in one second; PD20: provocative dose of histamine causing a $20 \%$ fall in FEV1; IgE: immunoglobulin E. No significant differences were observed between both groups of asthmatic patients, except for FEV1, which was at baseline significantly higher in the BDP group $(\mathrm{p}=0.02)$.
At baseline, no differences in RBC antioxidant enzymes were observed between the groups (table 2). In the BDP group, catalase levels could not be determined for two patients due to technical reasons. Smoking patients were equally distributed between groups (table 1); no differences in antioxidant levels were observed between smokers and nonsmokers (data not shown). Furthermore, no differences were observed in $\mathrm{Hb}$, white blood cell count and total number of eosinophils between the groups (table 1). At entry, for the whole group a significant positive correlation was observed between levels of glutathione peroxidase and glutathione S-transferase ( $\mathrm{r}=$ $0.51, \mathrm{p}=0.001$ ) and an inverse correlation for glutathione peroxidase and SOD $(r=-0.54, p<0.001)$. No significant correlations were observed between levels of antioxidant enzymes and baseline pulmonary function, levels of bronchial hyperresponsiveness, immunoglobulin (Ig)E or white blood cell parameters.

During treatment with BDP, a gradual increase in RBC catalase activity was observed, which reached statistical significance after 6 weeks (at entry (mean \pm SEM) $41 \pm 4 \mu$ mol $\mathrm{H}_{2} \mathrm{O}_{2} \cdot \mathrm{min}^{-1} \cdot \mathrm{g} \mathrm{Hb}^{-1}$, after 6 weeks $54 \pm 4 \mu \mathrm{mol} \mathrm{H}_{2} \mathrm{O}_{2} \cdot \mathrm{min}^{-1}$. $\mathrm{g} \mathrm{Hb}^{-1}, \mathrm{p}=0.05$ ) (figs. 1a and 2a). Interestingly, for total $\mathrm{RBC}$ glutathione an opposite change was observed; during BDP treatment, a gradual decrease in total glutathione levels was observed, which also reached statistical significance after 6 weeks of treatment (at entry (mean \pm SEM) $7.0 \pm 0.4 \mu \mathrm{mol} \cdot \mathrm{g} \mathrm{Hb} \mathrm{Hb}^{-1}$, at 6 weeks $6.6 \pm 0.3 \mu \mathrm{mol} \cdot \mathrm{g}$ $\mathrm{Hb}^{-1}, \mathrm{p}=0.04$ ) (figs. $1 \mathrm{~b}$ and $2 \mathrm{~b}$ ). No correlation was present between changes in catalase and total glutathione in $\mathrm{RBC}$. However, the increase of RBC catalase activity during treatment with BDP showed a weak inverse correlation with the initial level of $\mathrm{RBC}$ catalase activity $(\mathrm{r}=$ $-0.51, p=0.04)$. For changes in total glutathione, a similar trend was detected, although not statistically significant $(r=-0.42, p=0.08)$, Changes in the levels of catalase or glutathione were not correlated with pulmonary function, level of bronchial hyperresponsiveness or IgE. However, when the BDP group was divided into responders (increase in catalase at 6 weeks) and nonresponders (stable or decreased catalase), a significant difference was observed between the two groups in the number of eosinophils at entry (number of eosinophils at entry in nonresponders (mean \pm SEM) $153 \pm 52 \times 10^{6}$ cells $\cdot \mathrm{L}^{-1}$ versus responders $340 \pm 39 \times 10^{6}$ cells $\cdot L^{-1}, p=0.05$; fig. 3 ). No differences in pulmonary function, airway hyperresponsiveness or baseline antioxidant levels were present between responders and nonresponders. For glutathione, no differences in the

Table 2. - Baseline red blood cell antioxidant levels in asthmatic patients

\begin{tabular}{lll}
\hline & \multicolumn{1}{c}{ BDP } & \multicolumn{1}{c}{ Placebo } \\
\hline $\mathrm{SOD} \mathrm{U} \cdot \mathrm{mg} \mathrm{Hb}^{-1}$ & $1.14 \pm 0.09$ & $1.28 \pm 0.10$ \\
$\mathrm{GP} \mathrm{U} \cdot \mathrm{mg} \mathrm{Hb}$ & $3.27 \pm 0.38$ & $2.96 \pm 0.28$ \\
GST U.g Hb & $1.94 \pm 0.14$ & $1.85 \pm 0.15$ \\
Catalase $\mu \mathrm{mol} \mathrm{H} \mathrm{O}_{2} \cdot \mathrm{min}^{-1} \cdot \mathrm{g} \mathrm{Hb}^{-1}$ & $41.1 \pm 3.7$ & $47.1 \pm 3.3$ \\
Total glutathione $\mu \mathrm{mol} \cdot \mathrm{g} \mathrm{Hb}^{-1}$ & $7.01 \pm 0.35$ & $6.27 \pm 0.25$ \\
\hline
\end{tabular}

Data are presented as mean \pm SEM. BDP: beclomethasone dipropionate; SOD: superoxide dismutase; Hb: haemoglobin; GP: glutathione peroxidase; GST: glutathione-S-transferase. At baseline, no significant differences were observed between the two groups of asthmatic patients. 

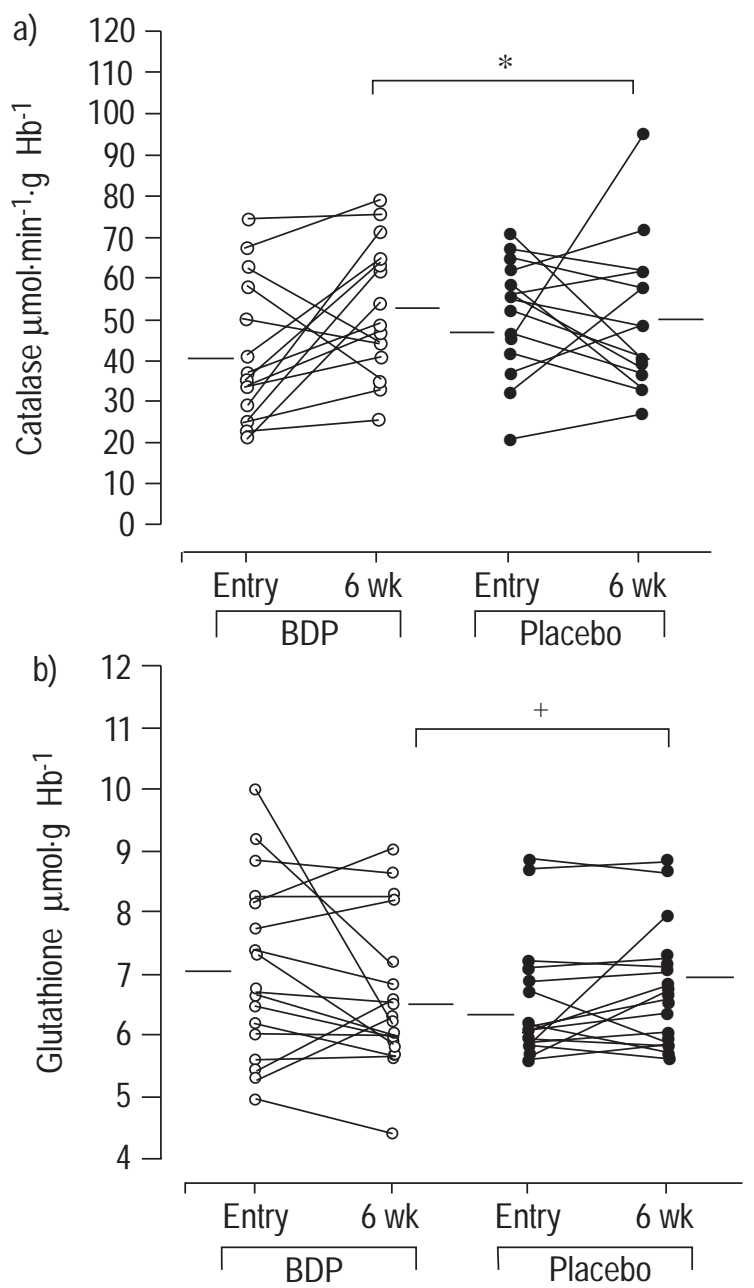

Fig. 1. - Beclomethasone dipropionate (BDP; 1,000 $\mu \mathrm{g} \cdot$ day $^{-1}$ ) induces a significant rise in red blood cell (RBC) catalase levels (a) and a decrease in RBC glutathione levels (b) of stable asthmatic patients after 6 weeks of treatment. Individual responses after 6 weeks of treatment are shown for the BDP and placebo treated patients. Horizontal bars represent the mean of the observed response. ${ }^{*}: \mathrm{p}=0.05 ;{ }^{+}: \mathrm{p}=0.04$.

number of eosinophils could be observed between responders and nonresponders.

Activities of SOD, glutatione peroxidase and glutathione S-transferase did not change during treatment with BDP (data not shown). Also, during treatment with BDP, no significant changes were observed in asthma symptom scores, use of $\beta_{2}$-rescue medication and pulmonary function, as reported previously [24].

During treatment with BDP, a significant decrease was observed in the total number of eosinophils in peripheral blood; this decrease was already observed after 2 weeks of treatment (at entry (mean \pm SEM) $318 \pm 33 \times 10^{6}$ cells $\cdot \mathrm{L}^{-1}$; after 2 weeks BDP $228 \pm 31 \times 10^{6}$ cells $\cdot \mathrm{L}^{-1} ; \mathrm{p}<0.02$ between groups) and number of eosinophils remained well below baseline levels during the rest of the study period (fig. 4).

\section{Discussion}

The present study demonstrates that erythrocyte levels of catalase increase and total glutathione levels decrease in patients with mild stable asthma, treated with BDP. Addi-
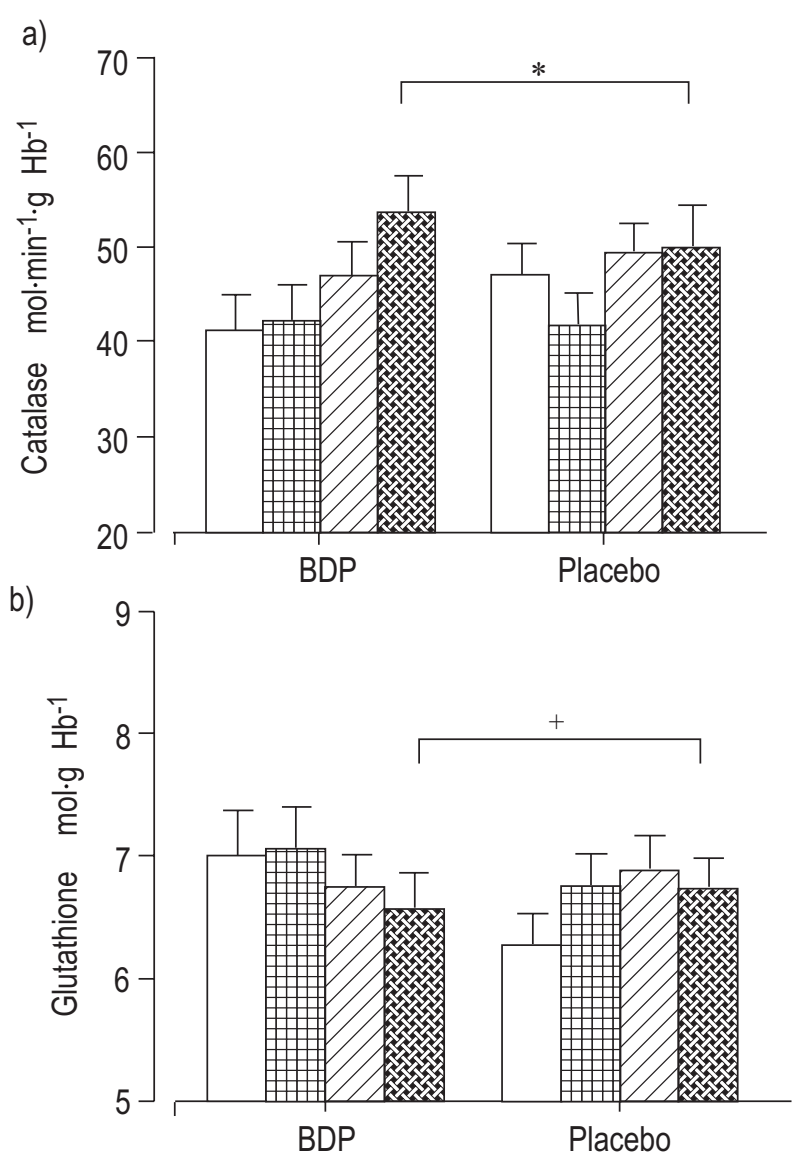

Fig. 2. - Changes in time in a) red blood cell (RBC) catalase and b) RBC glutathione in stable asthmatic patients, treated for 6 weeks with beclomethasone dipropionate (BDP; $1,000 \mu \mathrm{g} \cdot \mathrm{day}^{-1}$ ). Data are presented as mean \pm SEM of the two treatment groups at entry $(\square)$, after two weeks (曲), four weeks $(\mathbb{Z})$ and after six weeks (掣). ${ }^{*}$ : $\mathrm{p}=0.05 ;^{+}$: $\mathrm{p}=0.04$, a significant difference after 6 weeks between the two groups.

tionally, treatment with BDP resulted in a significant decrease in the total number of circulating eosinophils.

In asthma, numerous studies have shown that ROS are involved in the inflammatory process [1-7]. Alveolar macrophages of asthmatic patients demonstrated enhanced chemiluminescence, which correlated with asthma severity and bronchial hyperresponsiveness $[4,5]$. An increased oxidative burden has been noted, not only in the pulmonary compartment, but also in peripheral blood cells which generate higher levels of ROS both spontaneously and after stimulation in comparison to healthy controls. This has been observed for both blood polymorphonuclear neutrophils and monocytes [1, 2], and also for blood eosinophils [3].

Antioxidant levels increase in response to oxidant stress and can ameliorate oxidant induced injury [9]; knowledge of antioxidant defence levels is therefore essential to predict total outcome of tissue damage. In asthma, it has been shown that antioxidant levels are decreased, both in the pulmonary compartment $[23,31]$ as well as in peripheral blood $[1,12]$. RBC have been used to monitor long-term alterations in antioxidant status in chronic pulmonary disorders [16, 20], as well as in asthma [14].

In the present study, treatment with BDP resulted in an increase in RBC catalase activity, whereas no changes 


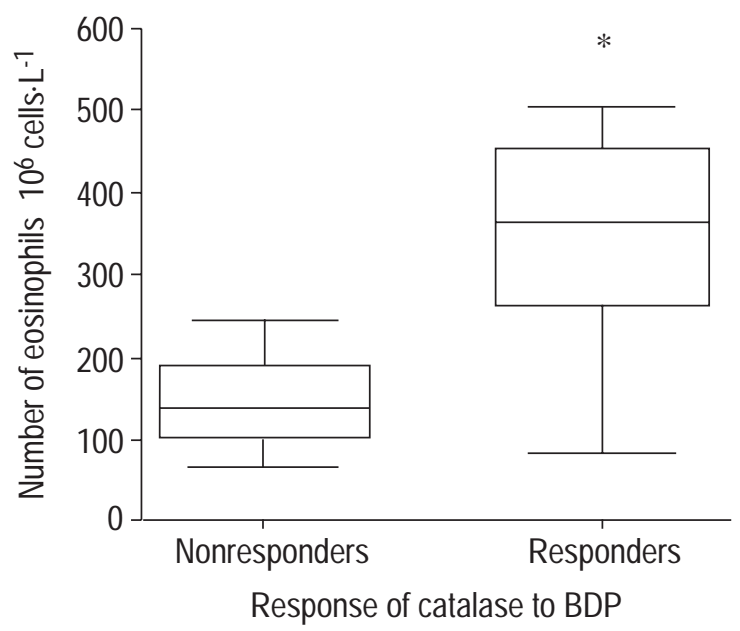

Fig. 3. - Boxplots (5th, 25th, 50th, 75th and 95th percentiles) showing that the number of peripheral blood eosinophils in responders (patients responding with a rise in red blood cell (RBC) catalase after beclomethasone dipropionate (BDP) treatment; $n=13$ ) was significantly higher than in nonresponders (i.e. stable or decreased catalase levels; $n=3$ ). $*: \mathrm{p}=0.05$.

were observed in levels of glutathione peroxidase, SOD and glutathione S-transferase. RBC express high levels of catalase in contrast to, for instance, bronchial epithelial cells [9]. Catalase is one of the most important mechanisms by which $\mathrm{RBC}$ dispose of $\mathrm{H}_{2} \mathrm{O}_{2}$ [17] and $\mathrm{RBC}$ catalase has been demonstrated to protect cells from ROS burden [17]. Therefore, the increase in RBC catalase in the present study reflects an increased defence against ROS exposure. The observed negative correlation of baseline catalase levels with the response of catalase to BDP treatment, observed in the present study, leads to the assumption that RBC catalase levels may be a marker of the asthmatic inflammation, where lower levels of catalase reflect enhanced exposure to ROS. Indeed in asthmatic children, catalase levels have been shown to be decreased in comparison to controls [14].

Several mechanisms may be involved in the effect of $\mathrm{BDP}$ on RBC catalase. Treatment with BDP attenuates the

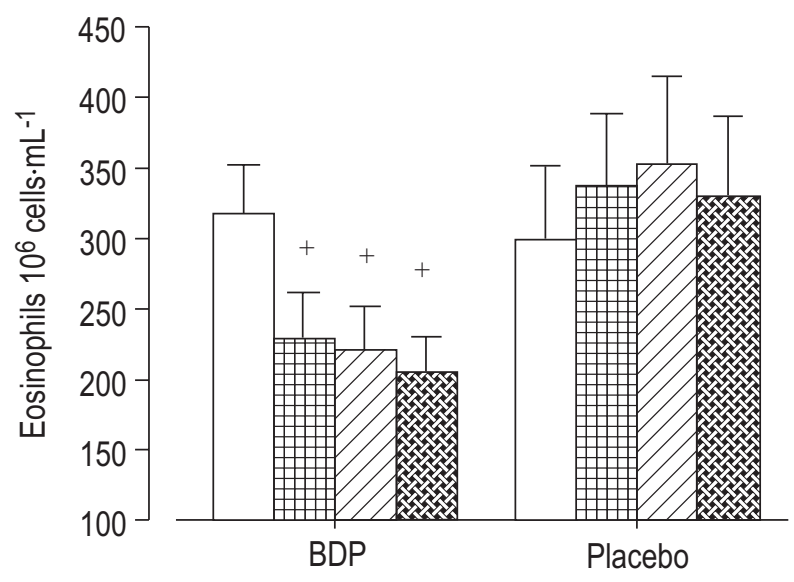

Fig. 4. - Beclomethasone dipropionate (BDP) induces a significant decrease in the number of circulating eosinophils in stable asthmatic patients. Data are presented as mean \pm SEM of the number of blood eosinophils during treatment with BDP or placebo. Data are for entry into study $(\square)$, after two weeks (曲), four weeks $(\mathbb{Z})$ and after six weeks (网) of treatment. ${ }^{+}: \mathrm{p}<0.02$ for BDP treated patients versus placebo. local inflammatory response as is shown in bronchial biopsies [32] and BAL [33]. This may lead to a reduction in the local formation of ROS. Recently, it was shown that monocytes of asthmatic patients, treated with inhaled steroids, produced less superoxide anions when stimulated with phorbol myristate-acetate (PMA) in comparison with monocytes of untreated asthmatic patients [34]. Furthermore, inhaled corticosteroids may decrease levels of inflammatory mediators, like transforming growth factor (TGF)- $\beta$, which normally inhibit antioxidant gene activity [31], resulting in increased gene transcription. Animal studies have shown that corticosteroids influence catalase gene-transcription. Dexamethasone has been shown in vitro to increase catalase messenger ribonucleic acid (mRNA) in perinatal rat lung cells [35] and to enhance SOD and glutathione peroxidase enzyme activity in the foetal rat lung [36]. Administration of corticosteroids in vivo increased catalase and glutathione peroxidase acti-vity in rat peritoneal macrophages and significantly inhibited in vitro hydrogen peroxide production in peritoneal macrophages [37]. Effects of corticosteroids on human cells are less clear. Although inhaled corticosteroids failed to influence ROS generation in stimulated alveolar macrophages [33], corticosteroids significantly reduced superoxide production in stimulated polymorphonuclear cells [38] and monocytes [34].

The present study also observed a reduction in $\mathrm{RBC}$ total glutathione during treatment with BDP. Few data exist regarding glutathione levels in $\mathrm{RBC}$ of asthmatic patients [14]. Both animal and human studies have shown that glutathione levels can increase during oxidant stress. Increased levels of glutathione were demonstrated in BAL of asthmatic patients [10], in RBC of patients with chronic occupational lung disorders [8] and in RBC of volunteers, participating in exercise training [21]. The decrease in RBC glutathione, observed in the present study, may therefore reflect decreased oxygen radical exposure. Indeed, animal studies have observed that corticosteroids decrease oxidative metabolism, followed by a decrease in antioxidant enzyme levels [39]. Another explanation for the observed decrease of total glutathione in the present study may be that GSSG is transported out of the RBC; however, this mechanism mainly occurs in heart and liver cells [9] and is only observed in RBC when exposed to very high levels of ROS. In addition, the observation of a decrease in RBC glutathione indirectly argues against systemic effects of inhaled BDP, since systemically applied corticosteroids have been shown in mice to increase hepatic synthesis of glutathione [40].

The present study demonstrated that patients responding to BDP with an increase in catalase, had higher eosinophil counts at entry than the patients not responding. In addition, the present study supports data from a previous study which also demonstrated a reduction in peripheral blood eosinophils during treatment with inhaled corticosteroids [41]. Since the number of blood eosinophils have been shown to correlate with asthma-severity [42], the present study suggests that patients with higher levels of inflammation show lower levels of RBC catalase and higher blood eosinophil counts. The fact that the present study did not observe changes in asthma-severity may be explained by the relative insensitivity of these parameters to monitor subtle inflammatory changes in patients with mild, stable asthma. 
In conclusion, the present study demonstrates that in patients with mild, stable asthma, treatment with inhaled beclomethasone dipropionate results in an increase in red blood cell catalase levels and, at the same time, a decrease in red blood cell glutathione. Peripheral blood eosinophil counts were higher in patients who demonstrated an increase in red blood cell catalase during treatment with beclomethasone dipropionate. It is speculated that inhaled beclomethasone dipropionate decreases reactive oxygen species generation within the lung, which leads to a subsequent change in systemic antioxidant levels. Further studies, simultaneously evaluating reactive oxygen species formation within the lung while monitoring antioxidant defences, will be needed in order to improve the understanding of the effects of inhaled corticosteroids on antioxidant defences in asthma.

Acknowledgements. The authors wish to thank E. Rhijnsburger and A. Knaapen (Department of Health Risk Analysis and Toxicology) and L. Baars (Department of Pharmacology) for their assistance with the analyses.

\section{References}

1. Vachier I, Damon M, Le Doucen C, et al. Increased oxygen species generation in blood monocytes of asthmatic patients. Am Rev Respir Dis 1992; 146: 1161-1166.

2. Vachier I, Chanez P, Le Doucen C, Damon M, Descomps B, Godard P. Enhancement of reactive oxygen species formation in stable and unstable asthmatic patients. Eur Respir J 1994; 7: 1585-1592.

3. Chanez P, Dent G, Yukawa T, Barnes PJ, Chung KF. Generation of oxygen free radicals from blood eosinophils from asthma patients after stimulation with PAF or phorbol esther. Eur Respir J 1990; 3: 1002-1007.

4. Cluzel M, Damon M, Chanez P, et al. Enhanced alveolar cell luminol-dependent chemiluminescence in asthma. $J$ Allergy Clin Immunol 1987; 80: 195-201.

5. Kelly C, Ward C, Stenton CS, Bird G, Hendrick DJ, Walters EH. Number and activity of inflammatory cells in broncho-alveolar lavage fluid in asthma and their relation to airway responsiveness. Thorax 1988; 43: 684-692.

6. Sanders SP, Zweier JL, Harrison J, Trush MA, Rembish SJ, Liu MC. Spontaneous oxygen radical production at sites of antigen challenge in allergic subjects. Am J Respir Crit Care Med 1995; 151: 1725-1733.

7. Barnes PJ. Reactive oxygen species and airway inflammation. Free Radic Biol Med 1990; 9: 235-243.

8. Borm PJA, Bast A, Wouters EFM, Slangen JJ, Swaen GMH, De Boorder TJ. Red blood cell antioxidant parameters in healthy elderly subjects versus silicosis patients. Free Rad Res Commun 1987; 3: 117-127.

9. Heffner JE, Repine JE. Pulmonary strategies of antioxidant defence. Am Rev Respir Dis 1989; 140: 531554.

10. Smith LJ, Houston M, Anderson J. Increased levels of glutathione in bronchoalveolar lavage fluid from patients with asthma. Am Rev Respir Dis 1993; 147: 1461-1464.

11. Durham SR, Carroll M, Walsh GM, Kay AB. Leucocyte activation in allergen-induced late-phase asthmatic reaction. $N$ Engl J Med 1984; 311: 1398-1402.

12. Malmgren R, Unge $\mathrm{G}$, Zetterstrom $\mathrm{O}$, Theovell $\mathrm{H}$, de Wahl K. Lowered glutathione peroxidase activity in asth- matic patients with food and aspirin intolerance. Allergy 1986; 41: 43-45.

13. Stone J, Hinks LJ, Beasley R, Holgate ST, Clayton BE. Reduced selenium status of patients with asthma. Clin Sci 1989; 77: 495-500.

14. Novák Z, Németh I, Gyurkovits K, Varga Sz I, Matkovics B. Examination of the role of oxygen free radicals in bronchial asthma in childhood. Clin Chim Acta 1991; 201: $247-252$.

15. Rahman I, Morrison D, Donaldson K, MacNee W. Systemic oxidative stress in asthma, COPD and smokers. Am J Respir Crit Care Med 1996; 154: 1055-1060.

16. Schins RPF, Keman S, Borm PJA. Blood antioxidant status in coal dust-induced respiratory disorders: a longitudinal evaluation of multiple biomarkers. Biomarkers 1997; 2: 45-50.

17. Agar NS, Sadrsadeh SMH, Hallaway PE, Eaton JW. Erythrocyte catalase; a somatic oxidant defence? J Clin Invest 1986; 77: 319-321.

18. Van Asbeck BS, Hoidal J, Vercelotti GM, Swarts BA, Moldow CF, Jacob HS. Protection against lethal hyperoxia by tracheal insufflation of erythrocytes; role of red cell glutathione. Science 1985; 227: 756-759.

19. Andersen HR, Nielssen JB, Nielsen F, Grandjean Ph. Antioxidative enzyme activities in human erythrocytes. Clin Chem 1997; 43: 562-568.

20. Engelen JJM, Borm PJA, van Sprundel M, Leenaerts L. Blood anti-oxidant parameters at different stages of pneumoconiosis in coal workers. Env Health Persp 1990; 84: $165-172$.

21. Evelo CTA, Palmen NGM, Artur Y, Janssen GME. Changes in blood glutathione concentrations, and in erythrocyte glutathione reductase and glutathione S-transferase activity after running training and after participation in contest. Eur J Appl Physiol 1992; 64: 354-358.

22. Barnes PJ. Anti-inflammatory therapy for asthma. Annu Rev Med 1993; 44: 229-242.

23. De Raeve HR, Thunissen FBJM, Kaneko FT, et al. Decreased $\mathrm{Cu}, \mathrm{Zn}-\mathrm{SOD}$ activity in asthmatic airway epithelium: correction by inhaled corticosteroid in vivo. Am J Physiol 1997; 272: L148-L154.

24. Pennings HJ, Wouters EFM. Effect of inhaled beclomethasone dipropionate on isocapnic hyperventilation with cold air in asthmatics, measured with forced oscillation technique. Eur Respir J 1997; 10: 665-671.

25. van Kampen EJ, Zijlstra WG. Determination of haemoglobin and its derivatives. Adv Clin Chem 1965; 8: 141-187.

26. McCord JM, Fridovich I. Superoxide dismutase. An enzymatic function for erythrocuprein (hemocuprein). $J$ Biol Chem 1969; 244: 6049-6055.

27. Aebi H. Catalase in vitro. In: Beutler E, ed. Methods in Enzymology. Vol. 105. New York, Academic Press, 1984; pp. 121-126.

28. Andersen ME. Determination of glutathione and glutathione disulfide in biological samples. Methods Enzymol 1985; 113: 548-555.

29. Habig WH, Jacoby WB. Assays for the differentation of glutathione S-transferases. Methods Enzymol 1981; 77: 398-405.

30. Brouwer EJ, Evelo CTA, Verplanke AJW, Welie RTH, De Wolff FA. Biological effect monitoring of exposure to 1,3-dichloropropene: effects on liver and renal function and on glutathione conjugation. Br J Ind Med 1991; 48: 167-172.

31. Smith LJ, Shamsuddin M, Sporn PH, Denenberg M, Anderson J. Reduced superoxide dismutase in lung cells 
of patients with asthma. Free Rad Biol Med 1997; 7: 1301-1307.

32. Djukanovic R, Wilson JW, Britten KM, et al. Effect of an inhaled corticosteroid on airway inflammation and symptoms in asthma. Am Rev Respir Dis 1992; 145: 669-674.

33. Duddridge M, Ward C, Hendrick DJ, Walters EH. Changes in bronchoalveolar lavage inflammatory cells in asthmatic patients treated with high dose inhaled beclomethasone dipropionate. Eur Respir J 1993; 6: 489497.

34. Majori M, Vachier I, Godard P, Farce M, Bousquet J, Chanez P. Superoxide anion production by monocytes of corticosteroid-treated asthmatic patients. Eur Respir $J$ 1998; 11: 133-138.

35. Clerch LB, Iqbal J, Massaro D. Perinatal rat lung catalase gene expression: influence of corticosteroids and hyperoxia. Am J Physiol 1991; 260: L428-L433.

36. Frank L, Lewis PL, Sosenko IRS. Dexamethasone stimulation of fetal rat lung antioxidant enzyme activity in parallel with surfactant stimulation. Pediatrics 1985; 75 : 569-574.

37. Pereira B, Costa Rosa LFBP, Safi SA, Bechara EJH, Curi
R. Hormonal regulation of superoxide dismutase, catalase and glutathione peroxidase activities in rat-macrophages. Biochem Pharmacol 1995; 50: 2093-2098.

38. Goldstein IM, Roos D, Weissman G, Kaplan HB. Influence of corticosteroids on human polymorphonuclear leucocyte function in vitro. Reduction of lysosomal enzyme release and superoxide production. Inflammation 1976; 1: 305-315.

39. Weglarz L, Drózdz M, Goss M. Effect of anti-inflammatory drugs on the activity of antioxidant enzymes and in vivo peroxidation products in the liver and kidney of rat. Comp Biochem Physiol 1990; 96C: 83-85.

40. Speck RF, Schranz C, Lauterburg BH. Prednisolone stimulates hepatic glutathione synthesis in mice. J Hepatol 1993; 18: 62-67.

41. Evans PM, O'Connor BJ, Fuller RW, Barnes PJ, Chung KF. Effect of inhaled corticosteroids on peripheral blood eosinophil counts and density profiles in asthma. $J$ Allergy Clin Immunol 1993; 91: 643-650.

42. Bousquet J, Chanez P, Lacoste JY, et al. Eosinophilic inflammation in asthma. N Engl J Med 1990; 323: 10331039. 